\title{
Effects of Fine LWA and SAP as Internal Water Curing Agents
}

\author{
Gemma Rodríguez de Sensale ${ }^{1), *}$, and Arlindo Freitas Goncalves ${ }^{2)}$
}

(Received August 16, 2013, Accepted April 29, 2014)

\begin{abstract}
Typical high-performance concrete (HPC) mixtures are characterized by low water-cementitious material ratios, high cement contents, and the incorporation of admixtures. In spite of its superior properties in the hardened state, HPC suffers from many practical difficulties such as its sensitivity to early-age cracking (which is associated with self-desiccation and autogenous shrinkage). In this context, conventional curing procedures are not sufficiently effective to address these limitations. In order to overcome this issue, two strategies, which are based on the use of internal reservoirs of water, have been recently developed. One of these strategies is based on the use of lightweight aggregates (LWA), while the other is based on the use of superabsorbent polymers (SAP). This paper studies and compares the efficiency of the LWA and SAP approaches. Moreover, some of the theoretical aspects that should be taken into account to optimize their application for internal curing of HPC are also discussed. Two fine LWA's and one SAP are studied in terms of autogenous deformation and compressive strength. Increasing the amounts of LWA or SAP can lead to a reduction of the autogenous deformation and compressive strength (especially when adding large amounts). By selecting appropriate materials and controlling their amount, size, and porosity, highly efficient internal water curing can be ensured.
\end{abstract}

Keywords: internal water curing, autogenous shrinkage, lightweight aggregates, superabsorbent polymers.

\section{Introduction}

Typical high-performance concrete (HPC) mixtures are characterized by a low water-cementitious material ratio (w/cm $<0.4)$, a high cement content, and the incorporation of admixtures. A characteristic of HPC's is its superior mechanical properties in the hardened state. But at the moment of application, some difficulties arise, mainly because of its sensitivity to early-age cracking, which is associated with self-desiccation and autogenous shrinkage (Bentz and Snyder 2009). Conventional curing procedures are not sufficiently effective to address this problem: they may eliminate the autogenous shrinkage in small crosssections but not in sections bigger than about $50 \mathrm{~mm}$ (Bentur 2000). In such conditions, differential strains may develop and aggravate the detrimental influence of autogenous shrinkage (Bentur and van Breugel 2002). In view of these limitations, several internal curing strategies have been recently developed, which this paper deeply analyses. In internal water cured concretes, the internal relative humidity

\footnotetext{
${ }^{1)}$ Instituto de Ensayo de Materiales-Instituto de la Construcción, Facultad de Ingeniería-Facultad de Arquitectura, Universidad de la República, 11200 Montevideo, Uruguay. *Corresponding Author; E-mail: gemma@fing.edu.uy ${ }^{2)}$ Departamento de Materiais, Laboratorio Nacional de Engenharia Civil (LNEC), Lisbon, Portugal.

Copyright $($ The Author(s) 2014. This article is published with open access at Springerlink.com
}

remains high and the shrinkage resulting from self-desiccation is limited or avoided (Philleo 1999; Bentz and Jensen 2004; 2007).

Since the internal curing of HPC is quite a complex phenomenon, the role of each factor in controlling its effectiveness is not always clear. Several studies have dealt with the experimental evaluation of the influence of lightweight aggregates (LWA) on autogenous shrinkage. Most of them assessed the use of coarse aggregates, but more recently, the use of fine LWA and superabsorbent polymers (SAP) has been explored (Bentz and Snyder 2009; Bentur and van Breugel 2002; 2007; Sahmaran et al. 2009; Cusson and Hoogeven 2008; Nestle et al. 2009; Craeye et al. 2011; Akcay and Tasdemir 2010). This paper reviews for the first time the efficiency of the SAP and fine LWA approaches, and considers some of the theoretical aspects which should be taken into account to optimize their use for internal curing of HPC.

Internal water curing affects the cement's degree of hydration, its internal water movement, and its autogenous deformation. Because of the difficulty in making accurate measurements of the degree of hydration and internal water movement, our experimental program will be based on the study of autogenous deformation.

Since one of the most important mechanical characteristics of concrete, especially in the context of HPC, is its compressive strength, it will be investigated in this manuscript.

\section{Internal Water Curing of Concrete}

Most HPC's contain insufficient mix water in order to maintain the water-filled coarse capillaries needed to sustain 
cement hydration and pozzolanic reactions. For this reason, it is generally accepted that methods based on water addition (internal water-supply) are more effective for this type of concrete. Since the internal curing water is a part of the system and it is finely dispersed, it can overcome the problems of low permeability and low $\mathrm{w} / \mathrm{cm}$ ratio, which harmfully affect the efficiency of traditional external curing methods. By this means, use of internal water supplies can be considered as the most effective method for reducing autogenous shrinkage, since it straightforwardly affects selfdesiccation (Japan Concrete Institute 1998).

According to the ACI 308 committee, "internal curing refers to the process by which the hydration of cement occurs because of the availability of additional internal water that is not part of the mixing water" (Kohler and Jensen 2007; Bentz et al. 2005). A number of natural or artificial materials that possess a significant internal porosity may be used as reservoirs for internal curing water.

In 1991, Philleo (1999) pioneered the idea that self-desiccation can be counteracted by the use of pre-saturated LWA. The properties of LWA that facilitate the internal curing process are: (i) its high porosity and open coarse pore structure, which allows fast water uptake when underwater, and (ii) the release of water in concrete sunder high internal relative humidity (Lura 2003). Several studies have dealt with the experimental evaluation of LWA on autogenous shrinkage (Philleo 1999; Lura 2003; Vaysburd 1996; Weber and Reinhardt 1996; Weber and Reinhardt 1997; Hammer 1992; Takada et al. 1998; Bentur et al. 2001). Most of the authors assessed the use of coarse aggregates, evaluating the influence of their content and degree of saturation.

The water content $\left(\mathrm{kg}\right.$ water $/ \mathrm{m}^{3}$ concrete) required to be introduced in the LWA in order to eliminate self-desiccation $\left(\mathrm{W}_{\mathrm{IC}}\right)$ can be calculated from chemical shrinkage (Bentz and Snyder 2009; Jensen and Hansen 2001; Zhutovsky et al. 2002) by Eq. (1):

$$
\mathrm{W}_{\mathrm{IC}}=C \cdot C S \cdot \alpha_{\max }
$$

where $C$ is the cement content, $C S$ is the chemical shrinkage (in $\mathrm{kg}$ of water per $\mathrm{kg}$ of cement hydrated), and $\alpha_{\max }$ is the maximum anticipated degree of hydration. Denoting the porosity of the LWA by $\phi$ and its saturation by $S$ $(0 \leq S \leq 1$, where 1 represents $100 \%$ saturation), the LWA content for internal curing, $\mathrm{V}_{\text {LWA }}$, can be calculated (Bentz and Snyder 2009; Zhutovsky et al. 2002) by Eq. (2):

$$
V_{\mathrm{LWA}}=\frac{W_{\mathrm{IC}}}{S \cdot \phi} \text {. }
$$

The ratio of this quantity to the volume fraction of fine aggregate in the original proportion is thus the required fractional replacement by LWA.

When coarse LWA is used, a relatively high replacement level of normal weight coarse aggregates is required in order to eliminate autogenous shrinkage; the content of LWA should be on the order of $500 \mathrm{~kg} / \mathrm{m}^{3}$ of concrete.

The use of fine LWA has been widely explored in the literature (Bentz and Snyder 2009; 2007; Sahmaran et al.
2009; Lura and van Breugel 2000; Zhutovsky et al. 2002). Evaluation of its use was reported in different studies which explore the possibility of eliminating autogenous shrinkage with contents that are smaller than the level required in the case of coarse aggregates. Fine fractions of LWA were found to be more effective in distributing available moisture for internal curing. If the particles are saturated with water before being incorporated into the concrete, they do not affect the initial water/cementitious ratio, but provide reservoirs of water that is released as the cement hydrates and "uses up" the initial mix water, thus minimizing the selfdesiccation of the cement (Alexander and Mindess 2005). To be suitable for this purpose, the fine aggregate must have a pore structure that makes it relatively easy for water to be absorbed, and then released (Lura et al. 2004). The water desorption of LWA is found between 85 and $98 \%$ at the $24 \mathrm{~h}$ of the absorption with humidity greater than $93 \%$ (Castro et al. 2011). Normalized plots of absorption and desorption of LWA demonstrate its benefits for use in internal curing. In addition, the fine aggregate should have approximately the same gradation as the natural sand that it is replacing, and should not have adverse affects on workability for the particle shape or texture (Alexander and Mindess 2005).

The basic principle for internal curing with LWA is that the largest pores will lose water first. The LWA pores are generally larger than the pores of the surrounding cement paste. As the pores in the paste decrease in size when hydration continues, the hydrating paste can pull water out of successively smaller pores of the LWA.

Another approach for internal water curing of concrete is based on the use of superabsorbent polymers (named SAP or hydrogels). SAP's can be produced by solution or suspension polymerization, to obtain particles of different sizes and shapes. For application in concrete: covalently cross-linked polymers of acrylic acid and acrylamide, neutralized by alkali hydroxide, have been proven to be efficient (Schröfl et al. 2012). SAP's made of covalently cross-linked acrylamide/acrylic acid copolymers were used for internal curing in the FIFA World Cup Pavilion, Germany. SAP's can be used as a means for introducing internal water reservoirs in order to eliminate autogenous shrinkage. This is owed to their ability to absorb amounts of water times their own weight, retain it, and release it when the conditions change. During concrete mixing, SAP particles absorb huge amounts of water from macro-inclusions containing free water. This free water is consumed during cement hydration, providing internal curing to the surrounding paste matrix and preventing self-desiccation.

A description of the use of SAP for internal water curing can be found in the literature (Kohler et al. 2007; Jensen and Hansen 2001; Jensen and Hansen 2002; Friedemann et al. 2006; Assmann 2013; Mechtcherine and Reinhardt 2012). The absorption and desorption in water and pore solutions appears to be well understood; however more data is needed regarding different types of SAP. According to Monning (2009), the water close to the surface of the polymers is lost rapidly. However, water closer to the core of the polymers 
must overcome more its side-chains, which interact with the water molecules through van-der-Waals forces. SAP starts releasing water after a setting time and appears to be completed after 1.5-2 days, depending on the cement paste and on the curing temperature, but there is still little knowledge to explain the mechanisms of internal curing of concrete using SAP, especially in the first few hours after the setting of concrete (Mechtcherine and Reinhardt 2012).

Relation between the molecular structure and the efficiency of SAP in the cement internal curing was recently studied in Ref. (Schröfl et al. 2012).The water absorption and desorption by SAP in concrete depends on its molecular structure. SAP materials of very high anionic functional group density take up the liquid quickly and release it back into solution (to a large extent) over the first one to $3 \mathrm{~h}$. Contrarily, SAP with lower anion density stores the absorbed liquid over the entire time.

Compared with LWA, the use of SAP has some particularities. SAP can be used as a dry concrete ingredient since it takes up water during the mixing process. The use of SAP allows free design of the pore shape and pore size distributions of the hardening concrete; however, the pores introduced by the SAP may be preferably selected in the range of 50-300 $\mu \mathrm{m}$. Potential problems with SAP addition include: change of setting and rheology, agglomeration of SAP particles, and grinding of SAP particles during mixing by to aggregate particles. For this reason the SAP to be used must be carefully chosen.

\section{Research Significance}

The purpose of this investigation is to compare the effects of LWA and SAP for internal water curing on autogenous deformation.

The degree of LWA saturation is very important on the effectiveness of the internal water curing. Usually full LWA saturation is reported in the literature. Since aggregate immersion in water at room temperature was found to be ineffective, in many studies the LWA grains were saturated in boiling water during a period of a few hours, or subjected to absorption under vacuum. But these techniques are not practical for on-site applications (Kohler and Jensen 2007; Lura 2003); for this reason, the experimental program in this manuscript includes a study of the influence of partial and full LWA saturation at room temperature.

\section{Experimental Program}

The experimental program was designed to study the LWA and SAP approaches, focusing on autogenous deformation and compressive strength, as described below.

The autogenous deformation was measured by a special measuring technique developed by Jensen and Hansen (Jensen and Hansen 1995). Linear measurements of autogenous deformation with digital dilatometers were performed. The dilatometric technique has been tested during years of research work on binder phases of HPC (Jensen and Hansen 2002; Jensen and Hansen 1995; Jensen and Hansen 1993;
Jensen and Hansen 1999). A particular characteristic of this measuring technique is the encapsulation of the hardening cement-based material in a specially designed, corrugated polyethylene mould; this effectively prevents moisture loss and ensures insignificant restraint during the hardening of the specimen. The employed technique is computer-controlled, and allows measurements immediately after casting, but its use is limited to aggregates with maximum size of $2.5 \mathrm{~mm}$. For this reason mortar specimens were used in this work.

The use of mortar mixture for the study of the internal water curing of HPC will lead to more shrinkage than that of concrete because concrete has more aggregate, restraining the shrinkable pastes (Holt 2005).

Mortars were prepared using a commercially-available ordinary Portland cement CEM I 42.5R manufactured in Portugal (properties are presented in Table 1), distilled water, natural sand (with a grain size distribution according ASTM C778-05 (ASTM C 2005)), and a polycarboxylic based high range superplasticizer with weigth fraction of solids in the solution of $38 \%$.

For internal water curing two LWA and one SAP were used. The two chosen LWÁs were markedly different in their pore structure. The first LWA is expanded clay commercially available -from Portugal- (referred as Clay Expanded Commercial, CEC); in this paper two different sizes of CEC were studied: particles in the range of $\mathrm{mm}$, and particles less than $2 \mathrm{~mm}$ with grain size distribution according to ASTM C778-05 (ASTM C 2005). The second, pumice, is a natural LWA obtained from volcanic rock whose porous structure is formed by dissolved gases that precipitate during the cooling as lava hurtles through the air; pumice from the island of Sao Miguel, Azores, Portugal was used; the pumice was divided into different fractions to obtain size fractions of crushed pumice $<2 \mathrm{~mm}$ and sieved; only particles in the range of 1 to $2 \mathrm{~mm}$ were studied with the aim of obtaining optimum efficiency to internal curing (Zhutovsky et al. 2002). The properties of both LWÁs and SEM images are presented in Table 2 and Fig. 1, respectively.

Figure 1a and $1 \mathrm{~b}$ show CEC with different sizes; it can be observed that those of smaller size show a more homogeneous shape, and the smaller particles show predominance of smaller pores. SEM observation of pumice shows that the shape of the pores varies from coarse and irregular to fine and rounded within different regions of the same sample.

The employed SAP is a white powder based on crosslinked polyacrylic sodium salt with corrosion inhibitor, commercially developed for wire and cable industry, as an economic method of water blocking cables. In contact with water or an aqueous solution SAP expands, and the powder turns into a translucent gel within a few seconds, filling a volume several times bigger than the initial one. SAP particle size was of $45-150 \mu \mathrm{m}$ and its specific gravity of $680 \mathrm{~kg} / \mathrm{m}^{3}$.

In order to investigate LWA and SAP in relation to internal water curing a total of eight mixtures were designed. Five mortars were made with normal weight aggregate, which was partly replaced by LWA with full and partial saturation 
Table 1 Characteristics of the cement used.

\begin{tabular}{|c|c|}
\hline & Cement \\
\hline \multicolumn{2}{|c|}{ Physical characteristics } \\
\hline Specific weight $\left(\mathrm{kg} / \mathrm{m}^{3}\right)$ & 3,120 \\
\hline Blaine specific surface $\left(\mathrm{m}^{2} / \mathrm{kg}\right)$ & 382.50 \\
\hline Fineness- $-45 \mu \mathrm{m}(\%)$ & 2.90 \\
\hline Water demand (\%) & 28.70 \\
\hline \multicolumn{2}{|c|}{ Chemical composition $(\%)$} \\
\hline $\mathrm{SiO}_{2}$ & 19.74 \\
\hline $\mathrm{Al}_{2} \mathrm{O}_{3}$ & 4.13 \\
\hline $\mathrm{Fe}_{2} \mathrm{O}_{3}$ & 3.27 \\
\hline $\mathrm{CaO}$ & 62.99 \\
\hline $\mathrm{MgO}$ & 1.90 \\
\hline $\mathrm{SO}_{3}$ & 3.02 \\
\hline $\mathrm{Na}_{2} \mathrm{O}$ & 0.00 \\
\hline $\mathrm{K}_{2} \mathrm{O}$ & 1.05 \\
\hline $\mathrm{Cl}^{-}$ & 0.04 \\
\hline Free lime & 1.43 \\
\hline Loss on ignition & 3.20 \\
\hline Insoluble residue & 0.90 \\
\hline \multicolumn{2}{|c|}{ Estimated compound composition (\%) } \\
\hline $\mathrm{C}_{3} \mathrm{~S}$ & 66.33 \\
\hline $\mathrm{C}_{2} \mathrm{~S}$ & 4.06 \\
\hline $\mathrm{C}_{3} \mathrm{~A}$ & 5.42 \\
\hline $\mathrm{C}_{4} \mathrm{AF}$ & 9.94 \\
\hline $\mathrm{CS}$ & 5.14 \\
\hline
\end{tabular}

Table 2 Properties of the LWA used.

\begin{tabular}{c|c|c}
\hline & Specific gravity $\left(\mathrm{kg} / \mathrm{m}^{3}\right)$ & $\phi(\%)$ \\
\hline \hline CEC & 1,200 & 35 \\
\hline Pumice & 570 & 46 \\
\hline
\end{tabular}

(three with CEC and two with Pumice). Two of the mortars contained different SAP content, and the last one was the reference mortar.

All mortars were prepared with a basic w/cm ratio of 0.30 , not including entrained water (in the reference mortar) according to ACI 308 committee, so additional internal water is not part of the mixing water (Sahmaran et al. 2009). Assuming for $\mathrm{w} / \mathrm{cm}=0.30$, a value for $\mathrm{CS}$ of $0.06 \mathrm{~kg} \mathrm{H}_{2} \mathrm{O}$ per $\mathrm{kg}$ cement hydrated according to ASTM C 1608-05 (ASTM 1608), and a maximum potential degree of hydration $\alpha_{\max }$ of 0.75 according to (Bentz and Snyder 2009), the amount of entrained water calculated from chemical shrinkage (using the Eq. 1), resulted equal to $(\mathrm{w} / \mathrm{cm})_{\mathrm{c}}=0.05$; this amount of entrained water was added to the mortars with LWA and SAP.

First, two LWA mixtures were designed considering the necessary total volume fraction of LWA calculated by Eq. (2) for CEC and pumice fully saturated (named CEC 1 and Pumice 1, respectively). LWA with the same grain size (1 $\mathrm{mm}<\mathrm{GS}<2 \mathrm{~mm}$ ) was used. Secondly, for fully saturated CEC, the effect of grain size was studied using CEC 1 and a new mixture named CEC $1 \mathrm{~A}$ with $\mathrm{GS}<2 \mathrm{~mm}$. For full LWA saturation the total volume fraction of LWA necessary calculated by Eq. (2) was used with the amount of entrained water calculated by Eq. (1).

To study the effect of partial saturation, two mortars were made with the same grain size $(1 \mathrm{~mm}<\mathrm{GS}<2 \mathrm{~mm})$, 

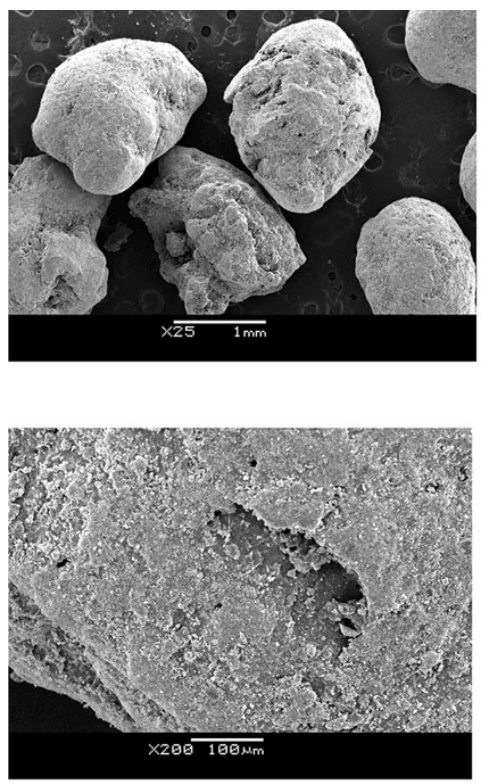

(a)

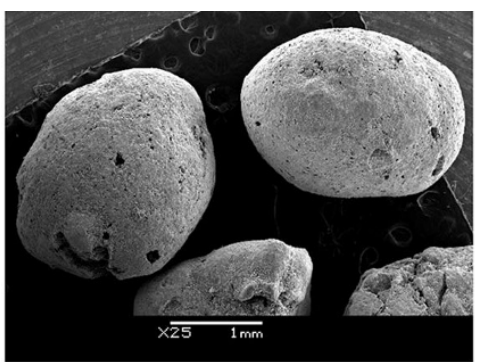

$\mathrm{x} 25$

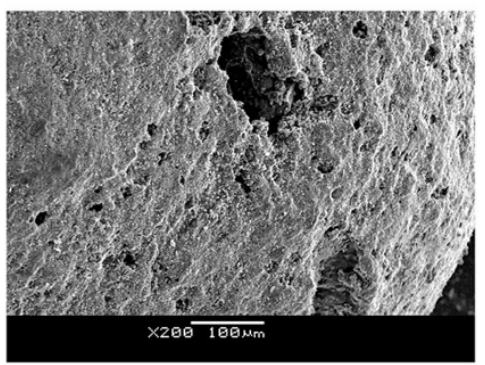

x 200

(b)
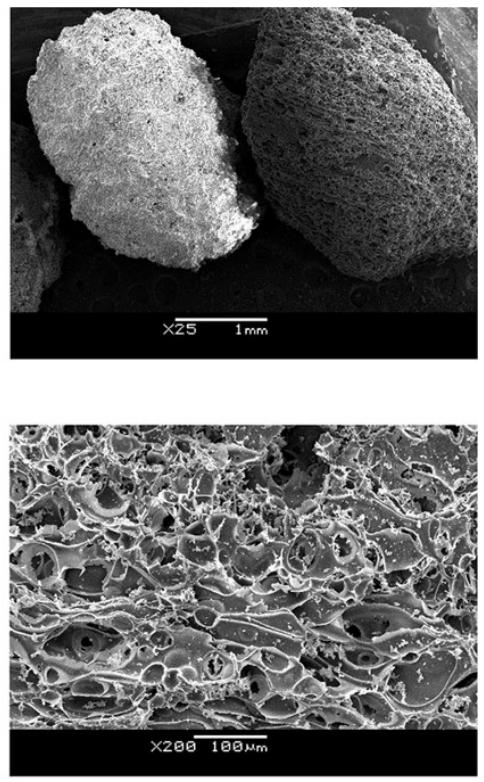

(c)

Fig. 1 SEM of the LWA used: a CEC, clay expanded with $1 \mathrm{~mm}<\mathrm{GS}<1.6 \mathrm{~mm}$; b CEC, with grain size $<2 \mathrm{~mm}$; $\mathbf{c}$ Pumice.

named CEC 2 and Pumice 2. The amount of entrained water to be used was calculated from chemical shrinkage using Eq. (1), we employed larger total volume fraction of LWA than the calculated by Eq. (2) (78 and $86 \%$ more, respectively); considering Eq. (2) we used saturations of aprox. $55 \%$ (56 and $54 \%$ for CEC and Pumice, respectively).

Finally two mixtures with SAP content of $0.3 \%$ and $0.6 \%$ of cement (by weight) were made and also a reference mixture. The SAP content was selected as the most usual in literature [,Jensen and Hansen 2002; Hoa Lam and Hooton 2005; Pierard et al. 2006 between others].

The cement/fine aggregate ratio was $1 / 2.125$ (aprox. 1/2) and the paste volume $49 \%$, for the slump requirements of the dilatometric technique (Jensen and Hansen 2002, 1995, 1993, 1999). The volumetric proportions of the mortars constituents for the eight tested mixtures are provided in Table 3. The individual volume fraction of the additional water added for internal curing of LWA and SAP mortars, which is not part of the mix water (Sahmaran et al. 2009), was 0.038 (corresponding to a amount of $37.5 \mathrm{~kg} / \mathrm{m}^{3}$ ); this amount was calculated from Eq. (1), with $(\mathrm{w} / \mathrm{cm})_{\mathrm{c}}=0.05$.

In the LWA the amount of entrained water was included $24 \mathrm{~h}$ before the preparation of mortars, while the SAP was pre-mixed with all ingredients at an air-dried condition to prevent gel-blocking in the mixture and the entrained water included with the mixing water. Due to the high alkalinity of the pore solution, the swelling capacity of the SAP in the mixture is reduced compared to tap water (Assmann 2013).

The mortars were prepared in a semiautomatic standard mortar mixer. Mixing was performed according to ASTM C305-99 (ASTM 1999) for the reference and the LWA mixtures, the superplasticizer was completely pre-dissolved in the mixing water. For the SAP mortars all dry ingredients were pre-mixed for $30 \mathrm{~s}$, the superplasticizer was added pre- solved with the water during the following $90 \mathrm{~s}$ of mixing. The total mixing time from first water addition was 5 for LWA and 8 min for LWA and SAP.

The superplasticizer dosage was the same in all mixtures ( $0.95 \%$ on anhydrous basis) by weight of cement. The slump of the fresh mortar was measured immediately after the mixing period. No external forces or vibration were applied in the test. The flow diameter obtained was $200 \pm 20 \mathrm{~mm}$, in all mixtures (required for the dilatometric technique according the literature (Assmann 2013; Mechtcherine and Reinhardt 2012)).

For each mixture two specimens were cast for autogenous deformation, each specimen was placed in a dilatometer computer-controlled, and linear measurements every $10 \mathrm{~min}$ were recorded in a room with controlled temperature at $20{ }^{\circ} \mathrm{C}$ continuously monitored.At early age thermal deformation occur simultaneously with autogenous shrinkage; for this reason a thermocouple was placed at the centre of each specimen (parallel specimen). Assuming a constant coefficient of thermal expansion $\alpha_{\text {avg }}=18.0 \times 10^{-6} \mathrm{~K}^{-1}$ (Jensen $2005)$, the autogenous deformation at early age was corrected by a term $\alpha_{a v g} \times \Delta T$ (Lura 2003; Friedemann et al. 2006; Jensen 2005) where $\Delta T$ is the change of the temperature between the dilatometer and the test specimens. The temperature of the dilatometer bench and those of the specimens were controlled to approximately $0.1{ }^{\circ} \mathrm{C}$ during the early age (1-2 days). In all cases measurements of autogenous deformation and internal temperature were carried out simultaneously.

$50 \mathrm{~mm}$ cubes were cast for compressive strength, for each mortar mixture. Cubes were made in steel moulds and demolded after 1 day, the density of all the mortars after demoulding are presented in Table 3; curing of the mortar specimens was conducted under sealed conditions at $50{ }^{\circ} \mathrm{C}$. The duration of the autogenous deformation test was 
Table 3 Volume fraction of mortar components in $1 \mathrm{~m}^{3}$ and density.

\begin{tabular}{c|c|c|c|c|c|c|c|c}
\hline & Cement & Mixing water & SP & Air & Sand & LWA & $\begin{array}{c}\text { SAP } \\
\text { Density (kg/ } \\
\left.\mathrm{m}^{3}\right)\end{array}$ \\
\hline \hline Reference & 0.240 & 0.225 & 0.015 & 0.01 & 0.51 & - & - & 2,286 \\
\hline CEC 1 $^{\mathrm{a}}$ & 0.240 & 0.225 & 0.015 & 0.01 & 0.42 & 0.09 & - & 2,161 \\
\hline CEC 1 $^{\mathrm{b}}$ & 0.240 & 0.225 & 0.015 & 0.01 & 0.42 & 0.09 & - & 2,123 \\
\hline CEC 2 $^{\mathrm{a}}$ & 0.240 & 0.225 & 0.015 & 0.01 & 0.35 & 0.16 & - & 2,078 \\
\hline Pumice 1 & 0.240 & 0.225 & 0.015 & 0.01 & 0.44 & 0.07 & - & 2,174 \\
\hline Pumice 2 & 0.240 & 0.225 & 0.015 & 0.01 & 0.38 & 0.13 & - & 1,951 \\
\hline SAP 0.3 \% & 0.240 & 0.225 & 0.015 & 0.01 & 0.507 & - & 0.003 & 2,284 \\
\hline SAP 0.6 \% & 0.240 & 0.225 & 0.015 & 0.01 & 0.504 & - & 0.006 & 2,260 \\
\hline
\end{tabular}

a $1 \mathrm{~mm}<\mathrm{GS}<2 \mathrm{~mm}$.

${ }^{\text {b }}$ GS $<2 \mathrm{~mm}$, distribution according ASTM C778-05.

28 days. The compressive strength tests were carried out at the age of 1,7 and 28 days.

\section{Results and Discussion}

\subsection{Autogenous Deformation}

The autogenous deformation results for CEC, Pumice, SAP and the reference mortars can be observed in Figs. 2, 3 and 4. Each deformation course has been adjusted to zero at the moment of setting (Philleo 1999; Jensen and Hansen

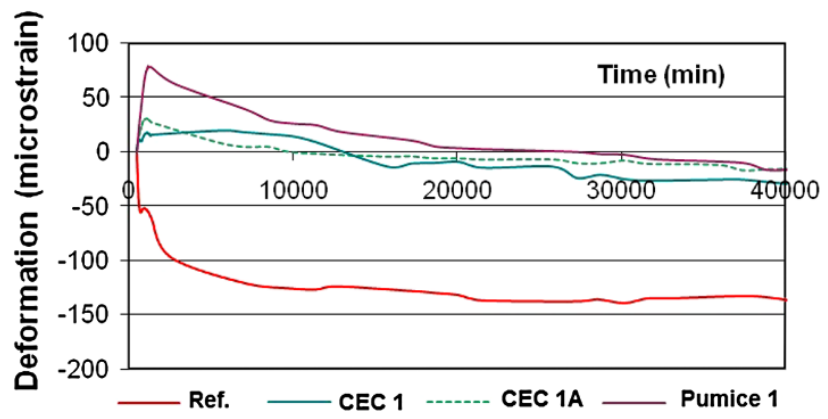

Fig. 2 Autogenous deformation from setting of mortars with LWA fully saturated and the total volume fraction calculated by Eq. (2).

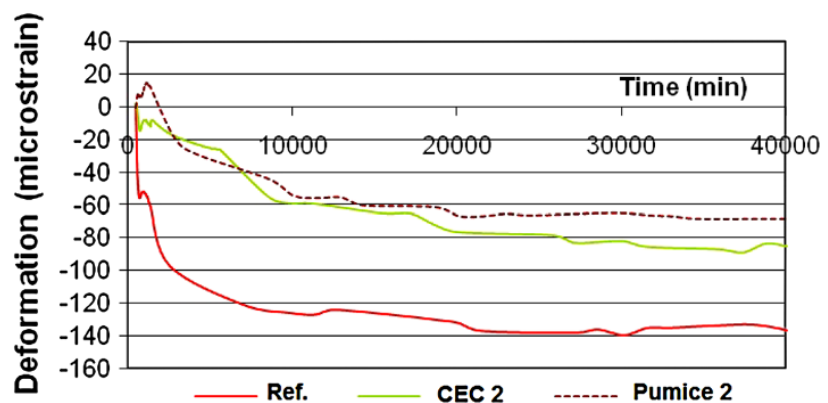

Fig. 3 Autogenous deformation from setting of mortars with LWA with the amount of entrained water calculated from chemical shrinkage, $1 \mathrm{~mm}<\mathrm{GS}<2 \mathrm{~mm}$, and higher volume fraction of LWA than the required by Eq. (2).
2002, 1993 Assmann 2013; Mechtcherine and Reinhardt 2012), which occurred approximately at $5 \mathrm{~h}$ after water addition.

Figure 2 shows the measured autogenous deformation for CEC and Pumice with the amount of entrained water calculated from chemical shrinkage as fully saturated. For different sizes of CEC aggregate with the same replacement of sand and entrained water (see CEC 1 and CEC 1A), similar results are presented. But the best effect was found with the smaller aggregate (GS $<2 \mathrm{~mm}$ ), in accordance with recent studies of water flow from expanded clays saturated with a concrete colored pigment solution and spatial distribution of LWA (Akcay and Tasdemir 2010). For the same grain size ( $1 \mathrm{~mm}<\mathrm{GS}<2 \mathrm{~mm}$ ), the autogenous shrinkage was basically eliminated by using the two LWA: CEC 1 and Pumice 1. This was probably a result of CEC and Pumice pore structure.

Figure 3 shows deformation for higher quantity of LWA (named CEC 2 and Pumice 2as in Table 3, with partial LWA saturation): a decrease of the autogenous deformation was observed in comparison with the reference. The results obtained with Pumice are better than those of CEC.

For full and partially saturated LWA (in Figs. 2 and 3) the best results are obtained with Pumice. Since the main purpose of the autogenous curing is water supply, the pumice (with large and well connected pores) is advantageous. This

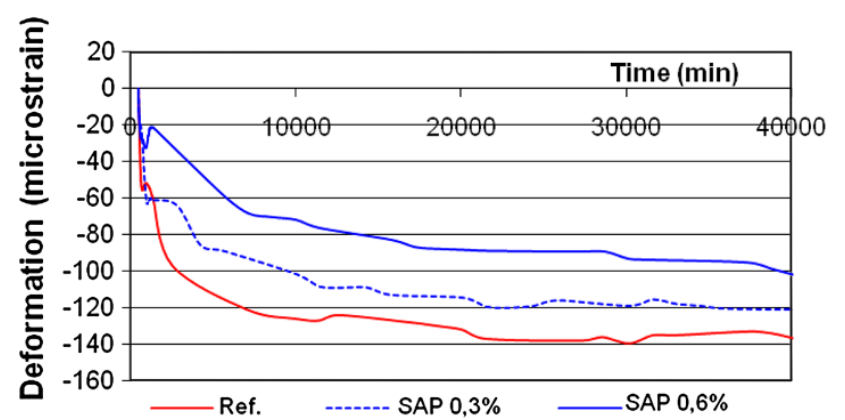

Fig. 4 Autogenous deformation from setting of mortars with different amounts of SAP. 
Table 4 Reduction of autogenous deformation (\%) at different ages in internally water cured mixtures.

\begin{tabular}{c|c|c|c|c}
\hline & 7 days & 14 days & 21 days & 28 days \\
\hline \hline CEC 1 & 112 & 93 & 82 & 88 \\
\hline CEC 1A & 100 & 96 & 48 & 38 \\
\hline CEC 2 & 53 & 42 & 98 & 89 \\
\hline Pumice 1 & 121 & 103 & 54 & 50 \\
\hline Pumice 2 & 57 & 50 & 15 & 12 \\
\hline SAP 0.3 $\%$ & 19 & 33 & 33 & 25 \\
\hline SAP $0.6 \%$ & 43 & & & \\
\hline
\end{tabular}

Table 5 Results obtained in compressive strength tests (MPa).

\begin{tabular}{c|c|c|c}
\hline Mixture & 1 day & 7 days & 28 days \\
\hline \hline Reference & 43.0 & 74.8 & 79.6 \\
\hline CEC 1 & 40.0 & 67.6 & 86.1 \\
\hline CEC 1A & 48.3 & 67.7 & 74.2 \\
\hline CEC 2 & 37.7 & 56.9 & 91.9 \\
\hline Pumice 1 & 47.1 & 76.9 & 75.5 \\
\hline Pumice 2 & 42.4 & 68.3 & 92.0 \\
\hline SAP 0.3 \% & 44.6 & 73.6 & 87.0 \\
\hline SAP 0.6 \% & 39.7 & 64.2 & \\
\hline
\end{tabular}

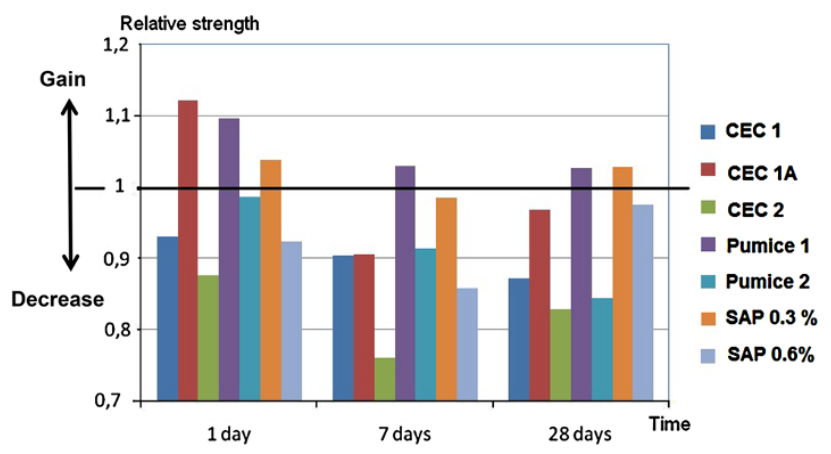

Fig. 5 Effect of the LWA and SAP on relative strength of internally water cured mixtures.

is due to the greater facility to store and output water in the pumice particles (ASTM 1999).

Figure 4 shows the autogenous deformation of mortars with different amounts of SAP. With no SAP addition, a considerable shrinkage, approximately 150 microstrain, is developed during 28 days of sealed hardening. Additions of 0.3 and $0.6 \%$ SAP led to a small and successive reduction of this shrinkage. However, with higher SAP content no complete elimination of autogenous deformation is achieved. The effect of SAP on the reduction of autogenous shrinkage of pastes was studied by Jensen and Hansen (2002), adding $0.3-0.6 \%$ SAP reduction of autogenous shrinkage, or even induced some expansion was obtained; the effect of $0.5,0.7$ and $0.9 \%$ SAP on concrete was studied for Craeye et al.
(2011), where full autogenous shrinkage was not obtained in agreement with the results obtained in the present work.

The performance of the SAP is influenced by the type of SAP used and their interaction with the cementitious environment (Schröfl et al. 2012; Assmann 2013). For the SAP used in this paper the water absorption capacity estimated by mortar spread test is $24 \mathrm{~g} / \mathrm{g}$; the SAP entrained less water than expected; a possible reason might be that a considerable amount of internal water curing is not released but rather is retained in the SAP. Unfortunately, on recent results published (Assmann 2013) is shown inefficient curing for pastes and concretes with the same type of SAP, result of less water absorption of this SAP at low w/c ratio, revealed from results of imaging analysis.

Based on the autogenous deformation results, Table 4 illustrates the reduction of autogenous deformation at different ages in the internally water cured mixtures. Partially saturated LWA showed less autogenous deformation than the reference mixture but higher than that of fully saturated LWA (caused by the difficulty of the water to be sucked from the inner pores). Fully saturated CEC and Pumice effectively mitigate both the early and 28 days autogenous deformation, as illustrated also in the Fig. 3. The type of SAP used was inefficient to avoid self desiccation, partial LWA saturation too.

\subsection{Compressive Strength}

The average value of the compressive strength results up to 28 days for both the references and the internal cured 
mixtures are given in Table 5. A good concordance between the three values of the cubic specimens on compressive strength was observed. The results showed an increase in mean values by increasing age.

The highest values of compressive strength at 1 day were reached by CEC 1A, Pumice 1 and SAP $0.3 \%$; at 7 days by Pumice 1; and at 28 days by the Pumice 1 and SAP $0.3 \%$ mixtures. Higher quantities of LWA or SAP show a decrease in compressive strength at all ages, as illustrated in Fig. 5; the cause of this decrease may be the low grain strength in comparison to the matrix strength and the presence of large voids.

The benefits of the use of Pumice 1 on the compressive strength development might be well illustrated by the relative strength (which represents the relation of the strength of the mixture at a given age to the strength of the reference mixture). The increased strength might be due to improvement of the interfacial transition zone, enhanced hydration due to internal curing, and absence of shrinkage-induced microcraking (Lura 2003; Lura et al. 2004).

\section{Conclusions}

This paper was focused on the use of two LWA and SAṔs for internal water curing. The main conclusions of this study are listed below:

- The addition of LWA reduces the autogenous deformation. The efficiency of the partial replacement of fine aggregates by different contents of LWA is very dependent of the size, the amount, the saturation degree and the porosity of the LWA particles. The addition of fully saturated LWA substantially reduces autogenous deformation and hence, mitigates the risk of early age cracking.

- SAP can be used as a means for introducing internal water reservoirs to eliminate autogenous shrinkage, but the SAP that will be used must be carefully chosen. Additions of 0.3 and $0.6 \%$ SAP led to a small and successive reduction of this shrinkage; however, with the highest employed SAP contents no complete elimination of autogenous deformation was obtained. The reduction of the autogenous deformation using SAP reported in this paper was much less than the reduction from the LWA.

- The employed amount of SAP was not effective to avoid self dessication, and neither was non-fully saturated LWA.

- Increasing the amount of LWA or SAP can lead to a reduction of compressive strength (specially with higher amounts).

- The importance of the pumice pore structure for the internal water curing was demonstrated. The use of full saturated pumice leads to lower autogenous deformations and higher compressive strength than the other mixtures.
The results indicate that by selecting appropriate materials and controlling the size, amount, porosity and saturation degree, highly efficient systems of internal curing can be obtained.

\section{Open Access}

This article is distributed under the terms of the Creative Commons Attribution License which permits any use, distribution, and reproduction in any medium, provided the original author(s) and the source are credited.

\section{References}

Akcay, B., \& Tasdemir, M. A. (2010). Effects of distribution of lightweight aggregates on internal curing of concrete. Cement \& Concrete Composites, 32, 611-616.

Alexander, M., \& Mindess, S. (2005). Aggregates in concrete. Colchester, UK: Taylor \& Francis.

Assmann A. (2013). Physical properties of concrete modified with superabsorbent polymers. PhD Tesis, Sttutgart University, Stuttgart, Germany.

ASTM C 16089-05. (2005). Test method for the chemical shrinkage of hydraulic cement paste. West Conshohocken, PA: ASTM International

ASTM C305-99. (1999). Standard practice for mechanical mixing of hydraulic cement pastes and mortars of plastic consistency. West Conshohocken, PA: ASTM International.

ASTM C 778-05. (2005). Standard specification for standard sand. West Conshohocken, PA: ASTM International.

Bentur, A. (2000). Early age cracking in cementitious systems. In V. Baroghel-Bouny \& P. C. Aitcin (Eds.), Shrinkage of concrete-Shrinkage 2000 (pp. 1-20). Lausanne, Switzerland: RILEM Publications PRO17.

Bentur, A., Igarashi, S., \& Kovler, K. (2001). Prevention on autogenous shrinkage in high strength concrete by internal curing using lightweight aggregates. Cement and Concrete Research, 31, 1587-1591.

Bentur A., \& van Breugel K. (2002). Internally cured concretes. In: A. Bentur Ed., Early age cracking in cementitious systems (pp. 295-306). Report of the RILEM Technical Committee 181-EAS.

Bentz, D. P., \& Jensen, O. M. (2004). Mitigation strategies for autogenous shrinkage cracking. Cement \& Concrete Composites, 26(6), 677-685.

Bentz, D. P., Lura, P., \& Roberts, J. W. (2005). Mixture proportioning for internal curing. Concrete International, $27(2), 35-40$.

Bentz, D. P., \& Snyder, K. A. (2009). Protected paste volume in concrete. Extension to internal curing using lightweight fine aggregate. Cement and Concrete Research, 29, 1863-1867.

Castro, J., Keiser, L., Golias, M., \& Weiss, J. (2011). Absorption and desorption properties of fine lightweight aggregate for application to internally cured concrete mixtures. Cement \& Concrete Composites, 33, 1001-1008. 
Craeye, B., Geirnaer, M., \& De Schutter, G. (2011). Superabsorbing polymers as an internal curing agent for mitigation of early-ae cracking of high-performance concrete bridge decks. Construction and Building Materials, 25, 1-13.

Cusson, D., \& Hoogeven, T. (2008). Internal curing of highperformance concrete with pre-soaked fine lightweight aggregate for prevention of autogenous shrinkage cracking. Cement and Concrete Research, 38, 757-765.

Friedemann, K., Stallmach, F., \& Karger, J. (2006). NMR diffusion and relaxation studies during cement hydration- $\mathrm{A}$ non destructive approach for clarification of the mechanism of internal post curing of cementitious materials. Cement and Concrete Research, 36, 817-826.

Hammer T. A. (1992). High strength LWA concrete with silica fume-Effect of water content in the LWA on mechanical properties. In Supplementary papers of the 4th CANMET/ ACI international conference on fly ash, silica fume, slag and natural pozzolans in concrete (pp. 314-330). Istanbul, Turkey.

Hoa L., \& Hooton R. D. (2005). Effects of internal curing methods on restrained shrinkage and permeability. In Proceedings of the 4th international seminar on self-desiccation and its importance in concrete technology (pp. 210-228). Lund, Sweden: Lund University.

Holt, E. (2005). Contribution of mixture design to chemical and autogenous shrinkage of concrete at early ages. Cement and Concrete Research, 35, 464-472.

Japan Concrete Institute. (1998). Report of JCI Committee on autogenous shrinkage of concrete. In Proceedings of international workshop on autogenous shrinkage of concrete (pp. 5-28). Hiroshima, Japan: JCI.

Jensen O. M. (2005). Autogenous phenomena in cement-based materials. Doctor of Science thesis, Department of Building Technology and Structural Engineering, Aalborg University, Aalborg, Denmark.

Jensen, O. M., \& Hansen, P. F. (1993). Autogenous deformation and change of the relative humidity in silica fume modified cement paste. ACI Materials Journal, 93, 539-543.

Jensen, O. M., \& Hansen, P. F. (1995). A dilatometer for measuring autogenous deformation in hardening Portland cement paste. Materials and Structures, 28, 406-409.

Jensen, O. M., \& Hansen, P. F. (1999). Influence of temperature on autogenous deformation and RH-change in hardening cemente paste. Cement and Concrete Research, 29, $567-575$.

Jensen, O. M., \& Hansen, P. F. (2001). Water-entrained cementbased materials-I. Principles and theoretical background. Cement and Concrete Research, 31, 647-654.

Jensen, O. M., \& Hansen, P. F. (2002). Water-entrained cementbased materials - II. Experimental observations. Cement and Concrete Research, 32, 973-978.

Kohler K., \& Jensen O. M. (2007). Internal curing of concrete, state-of-the-art Report of RILEM Technical Committee 196-ICC. RILEM Publications S.A.R.L., RILEM REPORT 41, Lausanne, Switzerland.

Lura P. (2003). Autogenous deformation and internal curing of concrete. PhD Thesis, Delft University of Technology, Delft, Netherlands.
Lura P., Bentz D.P., Lange D.A., Koules K., \& Bentur A. (2004). Pumice aggregate for internal water curing. In Concrete science and engineering: A tribute to Arnon Bentur (pp. 137-151). Bagneaux, France: RILEM Publications PRO36.

Lura P., Bentz D. P., Lange D. A., Kovler K., \& Bentur A. (2004). Pumice aggregates for internal water curing. In: Proceedings of the international RILEM symposium on concrete science and engineering (pp. 137-151). Lausanne, Switzerland: RILEM Publications PRO36.

Lura P., \& van Breugel K. (2000). Moisture exchange as a basic phenomenon to understand the volume changes of lightweight aggregate concrete at early age. In Shrinkage of concrete-shrinkage 2000, RILEM (pp. 533-546). Lausanne, Switzerland: Publications PRO17.

Mechtcherine V., \& Reinhardt H.W.(2012). Application of superarbsorbent polymers (SAP). In Concrete Construction. State of the Art Report prepared by RILEM Technical Committee 225-SAP. Berlin, Germany: Springer.

Monning S. (2009). Superabsorbing additions in concrete- applications, modeling and comparison of different water sources. $\mathrm{PhD}$ Thesis, University of Stuttgart, Stuttgart, Germany.

Nestle, N., Kuhn, A., Friedemann, K., Horch, C., Stallmach, F., \& Herth, G. (2009). Water balance and pore structure development in cementitious materials in internal curing with modified superabsorbent polymer studied by NMR. Microporous and Mesoporous Materials, 29, 51-57.

Philleo, R. (1999). Concrete science and reality. In J. P. Skalny $\&$ S. Mindess (Eds.), Materials Science of Concrete II (pp. 1-8). Westerville, OH: American Ceramic Society.

Pierard J., Pollet V., \& Cauberg N. (2006). Mitigating autogenous shrinkage in HPC by internal curing using superabsorbent polymers. In Volume changes of hardening concrete: testing and mitigation (pp. 97-106). Bagneux, France: RILEM Publication PRO52.

Sahmaran, M., Lachemi, M., Hossain, K. M., \& Li, V. C. (2009). Internal curing of engineered cementitious composites for prevention of early age autogenous shrinkage cracking. Cement and Concrete Research, 39, 893-901.

Schröfl, C., Mechtcherine, V., \& Gorges, M. (2012). Relation between the molecular structure and the efficiency of superabsorbent polymers (SAP) as concrete admixture to mitigate autogenous shrinkage. Cement and Concrete Research, 42, 865-873.

Takada K., van Breugel K., Koenders E. A. B., \& Kaptijn N. (1998). Experimental evaluation on autogenous shrinkage of lightweight aggregate concrete. In: Proceedings of international workshop on autogenous shrinkage of concrete (pp. 221-230). Hiroshima, Japan: JCI.

Vaysburd, A. M. (1996). Durability of lightweight concrete bridges in severe environments. Concrete International, 18, 33-38.

Weber S., \& Reinhardt H. W. (1996). A blend of aggregates to support curing of concrete. In Proceedings of international symposium on structural lightweight concrete (pp. 662-671). Sandefjord, Norway.

Weber, S., \& Reinhardt, H. W. (1997). A new generation of high performance concrete: concrete with autogenous curing. Advanced Cement Based Materials, 6, 59-68. 
Zhutovsky, S., Koler, K., \& Bentur, A. (2002a). Influence of wet lightweight aggregate on mechanical properties of concrete at early ages. Materials and Structures, 35, 97-101.

Zhutovsky S., Kovler K., \& Bentur A. (2002b). Efficiency of lightweight aggregates for internal curing of high strength concrete to eliminate autogenous shrinkage. In Early age cracking in cementitious systems, report of the RILEM Technical Committee 181-EAS (pp. 365-374). Lausanne, Switzerland. 